Pak. J. Agri. Sci., Vol. 53(1), 7-15; 2016

ISSN (Print) 0552-9034, ISSN (Online) 2076-0906

DOI: 10.21162/PAKJAS/16.4953

http://www.pakjas.com.pk

\title{
IMPACT OF DIFFERENT FARMING SYSTEMS (CONVENTIONAL, INTEGRATED AND ORGANIC) AND STORAGE TIME ON PHYSIOLOGICAL CHARACTERISTICS OF KINNOW MANDARIN (Citrus nobilis $\times$ Citrus deliciosa)
}

\author{
Tariq Mehmood*, Sarfraz Hussain, Umar Farooq and Kashif Akram \\ Institute of Food Science and Nutrition, University of Sargodha, Sargodha, Pakistan. \\ *Corresponding author's e-mail: tariq1491@gmail.com
}

\begin{abstract}
In advanced agriculture, non-conventional farming has been popularized very much. It is offering innumerable merits based on its practical application and societal acceptance. Current study was conducted to compare the impact of different farming systems cropping years and storage period on storage quality performance of Kinnow mandarin. Certain physiological characteristics of Kinnow mandarin including physiological loss of weight (PLW \%), fruit rottening (FR \%), chilling injury $(\mathrm{CI} \%)$ and peel pitting (PP \%) were studied during long cold storage (up to 90 days) at $4-6^{\circ} \mathrm{C}$. Significantly the lowest fruit rottening, chilling injury and peel pitting were observed in integrated Kinnow whereas the lowest physiological weight loss was found in the organically grown fruits. The results also revealed that the intensity of physiological rottening of Kinnow mandarin was significantly increased with the increasing of storage period (15-60 days). However, negligible changes were observed at the storage after 60 days. The organic and integrated Kinnow showed better and comparable physiological characteristics during cold storage. It can be perceived through reviewing the competitive performance of non-conventional (integrated and organic) fruit that there were prevailing equal opportunities of adopting and transferring into integrated and organic Kinnow production in Pakistan.
\end{abstract}

Keywords: Mandarins, farm practices, fruit storage, chilling injury, fruit rottening, peel pitting, physiological weight loss

\section{INTRODUCTION}

Citrus is one of the most diversified and economically important fruit commodities grown in more than 142 countries in diversified environmental conditions. Potentially it is grown in subtropical to tropical climates between $40^{\circ}$ North-South latitude. It has distinctive sensorial, physico-chemical and nutritional characteristics along with unique medicinal value and economic importance. After grapes it stands on $2^{\text {nd }}$ rank contributing over 70 million tons per annum and occupies $1^{\text {st }}$ position in terms of trade revenue of fresh fruits (FAO, 2012). Citrus group is most diversified having wide range of cultivars. By inheritance it is the most challenging fruit to improve its genetics or varietal behavior because of complicated breeding and reproductive biology which frequently inhibit its sexual hybridization and zygotic segregation (Grosser et al., 2000). Citrus trees are vigorous, tall and columnar and can be characterized as ever green plants ideally grown in Mediterranean Hemisphere. These are white flowering plants having numerous long, slender, ascending and virtually thorn less shoots. Its dense foliage consists of medium, large broad lanceolate complete leaves. Citrus fruit is non-climacteric in nature and ripens on the tree. It is poorly chilling resistant and unable to tolerate cold climate $\left(<3^{\circ} \mathrm{C}\right)$ in the field, however it gives satisfactory response in hot climate regions (Malik, 1994).

The productivity and quality of citrus fruit depends upon the implementation of integrated crop management practices in which all biotic (rootstock, cultivar, insect pest and disease management) and abiotic (climate, site, soil, irrigation and nutrition management) factors are necessarily involved (Iglesias et al., 2007). Kinnow Mandarin is the most flavored and aromatic citrus member predominantly grown in Pakistan but is unable to fetch the competitive earning because of certain quality, safety and storage problems. Low quality, poor presentation, high seed number, mono-culture, squeezed supply window and zero certified nonconventional (integrated and organic) production can be the potential factors of its poor penetration and low earning in high value markets (PHDEC, 2014). Most of the intimidating factors can be addressed and resolved effectively through transitioning the conventional production system into integrated and organic (Ioannis et al., 2004). Non-conventional such as integrated and organic Kinnow production can be the easiest and shortest approach to improve fruit yield or quality, product safety and ultimately high cash stream in national revenue. In current scenario, in Pakistan very low per unit earning has compelled growers to replace the old conventional farming with some advance 
integrated and organic systems. . High $\mathrm{pH}$ value and low cumulative organic matter $(<0.3 \%)$ in soils are not only lowering the natural productivity but also reducing the efficacy of most of external inputs like fertilizers, pesticides and other nutrients. Relatively high input costs and lower outcome in conventional production system also motivating stakeholders towards replacing it with other cost effective and quality efficient farming methods (Willer and Kilcher, 2011).

Pakistan is blessed with four distinctive environments, naturally enriched soils and sufficient supply of fit canal irrigation. These beneficial attributes can be used effectively to motivate the growers to replace the conventional farming modern systems to maximize per unit earning and to improve quality of life. Competitive performance of both integrated and organic Kinnow mandarin with respect to farming practices, storage life and cropping years can also be highlighted to satisfy the growers for adopting these successful alternative farming systems. Considering forgoing facts a study was planned and conducted to transform the conventional methods into integrated and organic system. It was also focused to compare the cold storage performance of Kinnow mandarin grown through conventional, integrated and organic farming systems.

\section{MATERIALS AND METHODS}

Selection of research site: Pre-harvest research component of current study was conducted at Wahdat Citrus Farm (WCF) situated in 24 SB Lahore Road Sargodha Punjab, Pakistan. WCF was consisting of 63 hectares mainly grown with Kinnow mandarin having plant age of 15-18 years. Experimental site was selected on the basis of information collected from different concerning departments and field survey conducted before start of current study. Orchard was divided into three blocks of 20 acres each and was randomly marked as B-I (Conventional), B-II (Integrated), and B-III (Organic). All blocks were maintained separately with minimum $120 \mathrm{ft}$ barrier zone to comply different production systems and requirements. Conventional block (B-I) was maintained as controlled block which was mainly cultivated through following the recommendations of Malik (1994). Whereas, both integrated (B-II) and organic (B-III) blocks were managed through the standard guidelines and recommendations suggested by different organizations including International Federation of Organic Agricultural Movement (IFOAM), United States Department of Agriculture (USDA), National Organic Standard Board (NOSB) USA and Canadian Food Inspection Agency (CFIA) etc.

Global GAP certification of research site: Wahdat Citrus Farm was managed through observing the standard guidelines and general regulations of Global GAP with reference of Integrated Farm Assurance Crops Version
4.0_Mar13/Control Points and Compliance Criteria AF Version 4.0-2_Mar2013. All inputs and cultural practices were controlled and their data was maintained on farms record register for three years. On the basis of compliance of standard, orchard was qualified in Global GAP certification with registration number of 40499283705254052852799614 under option 2 with PMO (Produce Marketing Organization) of Chase International.

Harvesting and sample collection: On the basis of maturity indices like intensity of fruit rind color, sugar contents, physical ripeness, and fruit soundness, harvesting was planned on January, 18-22 during each study year (2012-14). In current study randomized sampling technique was applied and randomly 20 fruits from each plant were picked with light picking scissor separately around the whole plant canopy to avoid biasness and homogenize the sample without damaging the small button stock on the collar end of fruit. Total 1000 fruits from each block were harvested in plastic baskets and were shifted into Roshan Enterprises 6Km Kotmoman Main Road Bhalwal Sargodha, Pakistan for further studies. Samples were collected for consecutive three years to study the impact of farming practices and cropping years on storage performance of Kinnow mandarin.

Processing and storage of Kinnow fruit: After necessary washing, drying and sorting the fruits were subjected for waxing where polyethylene based food wax @ 1liter/ton mixed with recommended fungicide Thiabedazole (TBZ) @ $800 \mathrm{ppm}$ was applied. After drying at $45-50{ }^{\circ} \mathrm{C}$ and final sorting and grading, the fruits were packed into $10 \mathrm{Kg}$ corrugated boxes having 42, 48, 54, 60, 72 and 80 possible fruit counts. After weighing, sticking, stripping and marking 50 boxes of each treatment were shifted into cold store on homogenous storage conditions of $4-6^{\circ} \mathrm{C}$ and $85-90 \%$ relative humidity $(\mathrm{RH})$. The fruit data was recording after 15 days interval during the whole storage period (90 days).

Physiological Study of Kinnow Mandarin during Storage:

Physiological loss of weight (PLW \%): Physiological loss of weight (PLW) was noted during the whole storage as was suggested by Thakur et al. (2002). Fruit from each treatment were marked randomly and sample size was $30 \quad(n=30)$ fruits. The difference in weight was considered as the physiological loss of weight (PLW\%) and the results were expressed as percent loss as given below:

$$
\begin{aligned}
& \text { Physio. Loss of } \\
& \text { Wt. }(\text { PLW\% })
\end{aligned}=\frac{\text { Original Fruit Wt. }- \text { Fruit Wt. after } 15 \text { days }}{\text { Original Fruit Wt. }} \times 100
$$

Peel pitting (PP \%): Peel pitting (PP), brown/dark necrotic circles on the fruit surface were calculated following the procedure suggested by Sala et al. (2005). Thirty fruits from each treatment were randomly selected and peel pitted fruits were counted. Afterwards, the effected count was divided 
with total selected number of fruit $(n=30)$. The results were calculated through following expression:

$$
\begin{aligned}
& \text { Peel Pitting } \\
& (\mathrm{PP} \%)
\end{aligned}=\frac{\text { Total Peel Pitted Fruits in Treatment }}{\text { Total No. of Fruits in that Treatment }} \times 100
$$

Fruit rottening (FR \%): Physiological rottening of Kinnow or any incident of rottening or appearance of green mould spot on the peel surface was counted in each treatment to calculate its infestation pattern. The method used in present study was suggested by Chopra et al. (2004) with slightly modified given below:

$$
\begin{aligned}
& \begin{array}{l}
\text { Fruit Rottening } \\
(\text { FR\% })
\end{array}=\frac{\text { No. of Rotten Fruits / Treatment }}{\text { Total No. of Fruits in Specific }} \times 100 \\
& \text { Treatment }
\end{aligned}
$$

Chilling injury (CI \%): Chilling or blast injury in Kinnow mandarin was calculated when samples were subjected for long storage time (90 days) at control temperature $4-6^{\circ} \mathrm{C}$ as was described by Lafuente et al. (1997). Chilling injury percentage was calculated by examining large brown depressions along the fruit surface and counting total number of fruits showing the CI symptoms.

$$
\begin{aligned}
& \text { Chilling } \\
& \text { Injury (CI\%) }
\end{aligned}=\frac{\text { No. of Effected Fruits / Treatment }}{\text { Total No. of Fruits in Specific Treatment }} \times 100
$$

\section{RESULTS AND DISCUSSION}

There are many attributes responsible for different physiological disorders and shelf life of fruits and vegetables but long storage at low temperature is the potential reason of quality deterioration in most of perishable fruits (Ozdemir et al., 2008). Various studies also suggest that citrus cultivars grown on poor soils are more liable to cold store breakdown than well fertile, sustainable and nutritionally balanced soils (Camin et al., 2011). Harvesting maturity, time and methodology also play very critical role in storage life and physiological aspects of the fruit. Additionally, varietal and genetic distinctiveness have equally important role in susceptibility of cold treatment and storage period. It has been also reported that most of citrus cultivars having more number of seeds performed more satisfactorily during long storage against certain physiological and rind disorders than others (Roussos, 2011).

Physiological Loss of Weight (PLW) of Kinnow mandarin: The results regarding physiological weight loss revealed that all the farming practices and storage period significantly impacted the PLW (\%) and storage performance of Kinnow mandarin. The effect of cropping years on PLW (\%) and all first order interactions were found to be non-significant. The results also illustrated that the highest PLW (\%) was observed in conventionally grown fruit whereas the lowest in organically grown fruit. Kinnow fruit grown through integrated method exhibited $0.14 \%$ less PLW (\%) than conventional and $0.07 \%$ more than organically grown fruit after 90 days of storage (Fig. 1).

The results of current study demonstrated that PLW (\%) was significantly increased with prolonging the storage period. Significantly the highest PLW (\%) was noted after 75 days of low temperature storage, while, the lowest PWL (\%) was recorded during start of storage period (0-15 days). The results also explained that during long storage (90 days) the percentage of PLW was lower than earlier storage loss. It can be concluded that the percentage of PLW was reduced or fixed after certain time of storage as shown in Figure 2.
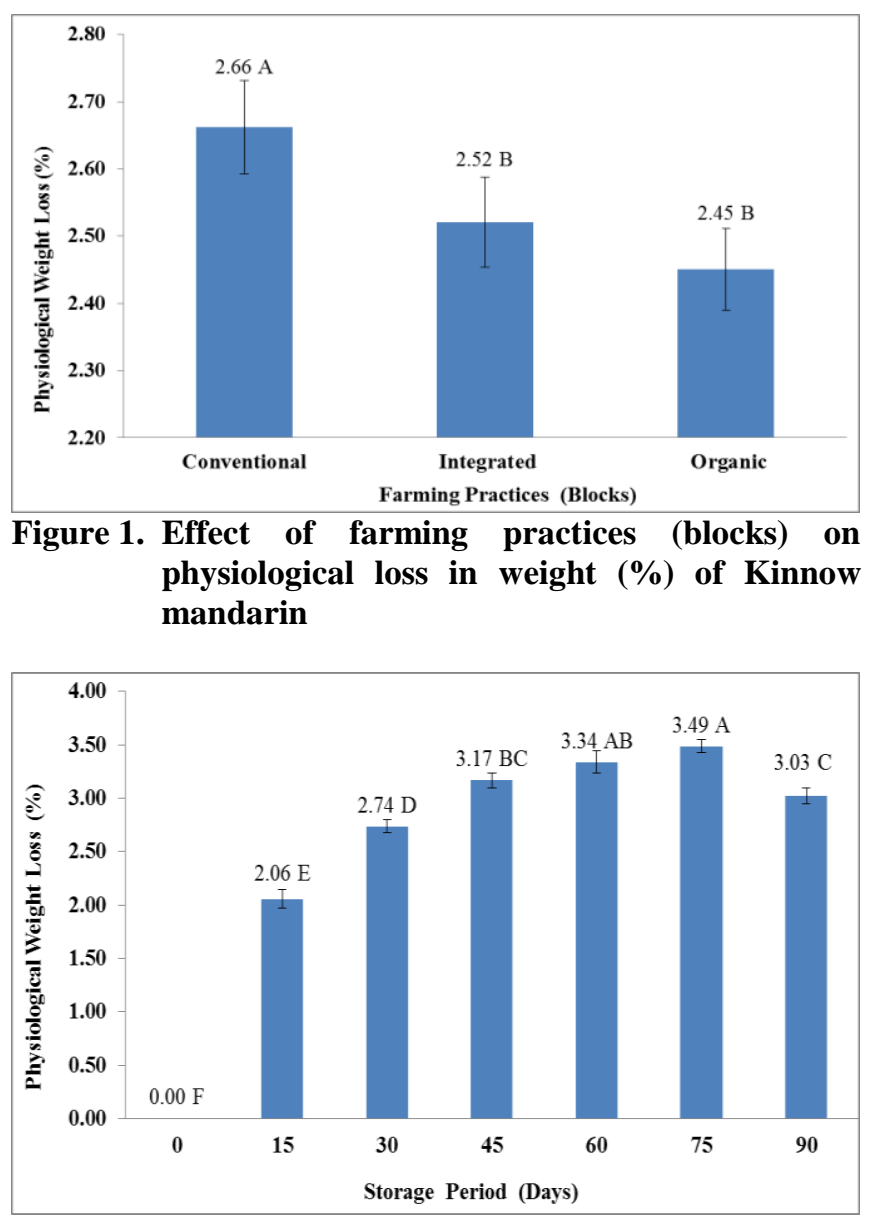

Figure 2. Effect of storage period (days) on physiological loss in weight $(\%)$ of Kinnow mandarin

The results of current study were agreed with the conclusion of Rajendra et al. (2013) who described that organically produced lime had comparatively less PLW (\%) and other physiological characteristics than lime grown through conventional and integrated production practices. Application of chemical fertilizers resulted in increased PLW (\%) in sweat potato during long storage. It was also 
expressed that application of imbalanced fertilizers caused high PLW (\%) and deterioration of post-harvest quality of fruit during storage (Gichuhi et al., 2014). Ranjit and Paul (2013) reported that organically grown tomatoes had less PWL (\%) as compared to inorganic fruits. Biruk et al. (2014) concluded that integrated farming potato had higher quality yield and shelf life than conventionally grown fruits. Application of chemical fertilizers and broad spectrum pesticide may have caused the deterioration of fruit quality and its storage life. Chemically grown fruits may have course rind due to imbalanced use of nutrients. Defective fruit rind might have caused the excessive loss of moisture during long storage and ultimately high PLW (\%) as compared to the fruit grown through integrated and organic farming systems. In both non-conventional farming systems soils improve its fertility due to balanced fertilizers and maximum releasing and absorption of fixed nutrients.

In current study, it was observed that PLW (\%) was increased with increasing of storage period at certain level such that significantly the highest weight loss was noted at 75 storage days. These results were in line with the findings of Jan and Rab (2012) who described that long fruit storage resulted in flavor disliking and high physiological weight loss. It was also concluded that in most of the fruits the PLW (\%) was increased during long storage. Rab et al. (2010) also conducted a same study and concluded that in citrus oranges (Citrus sinensis) both of the instrumental and noninstrumental characteristics were significantly changed during different storage intervals. They described that during early fruit storage (15 days) the PLW was only $1.38 \%$ which was increased up to $27.55 \%$ during long storage of 75 days. Candir et al. (2013) also concluded the same results that maximum PLW (\%) in citrus fruit was observed during long storage of 5 months.

Many other studies on different fruits also concluded the same observations that post-harvest quality changed when fruits were subjected for long cold storage. Marcilla et al. (2006) evaluated the storage performance of apple and concluded that most of the post-harvest quality attributes were significantly affected when fruit was stored on lower temperature $\left(5\right.$ to $\left.15^{\circ} \mathrm{C}\right)$ for certain time interval. The moisture and subsequent physiological weight loss in fruits was increased linearly with increasing in storage duration. Ali et al. (2011) concluded that different quality characteristics of the fruits were significantly changed during long storage. The fruit exhibited maximum shelf life at $0^{\circ} \mathrm{C}$ which was decreased with increasing storage time interval.

In the light of current study and consulting with different reviews it can be concluded that in Kinnow fruit both farming practices and storage time interval impacted significantly on its post-harvest life respective to physiological loss of weight.
Fruit rottening percentage (FR \%) of Kinnow mandarin: The results presented in Figure 3 revealed that fruit rottening (FR \%) in Kinnow mandarin grown through conventional, integrated and organic farming practices was significantly changed during cold storage. The results further illustrated that significantly the highest fruit rottening was noted in organic Kinnow whereas the lowest in integrated Kinnow mandarin. Conventionally grown fruit showed $0.1 \%$ fruit rottening very close to organic during long storage of 90 days.

Integrated Kinnow performed excellently in current studies with respect to FR (\%) during long storage which might be because of that in integrated farming best combination of both conventional and organic practices was used during pre-harvest practices. So the best application of both integrated pest management and integrated crop management might have developed good quality compacted fruit having resistance and tolerance against fruit spoilage. Citrus orchard having good management practices might have enhanced the plant health, fruit quality and ultimately post-harvest storage life. Peter et al. (2002) described the same observations that fruit grown through integrated farming had higher quality and lesser FR\% during cold storage than others. Integrated fruit had significantly lower fruit spoilage and higher nutritional values than conventionally grown fruits. The findings of Hajslova et al. (2005) were also agreed with the results of current study that integrated farming system had preferred quality tendency with respect to FR\% and storage life. Furthermore, integrated practices caused to produce enriched fruits with balanced nutrition and responded well regarding FR during long storage. Roth et al. (2007) conducted same research work and concluded that Kinnow grown through integrated farming had higher quality and lower FR\% during cold storage than others.

Results presented in Figure 4 expressed that FR\% in Kinnow was increased with increasing of storage period such that maximum fruit spoilage was observed when fruit was stored at 90 days and the lowest rottening was noted during early storage of 15 days. Comparatively high FR \% was observed during 15-60 days of fruit storage than rottening percentage observed during 75- 90 days of storage.

These findings can be explained with D'Aquino et al. (2007) concluded that FR \% in sweet oranges was increased with increasing of storage period which could be as high as $50 \%$ when fruit was subjected to long storage. Smilanick et al. (2006) described that post-harvest rottening in perishable fruits treated with different fungicides were typically low about $2-4 \%$, whereas without chemical application or refrigeration losses reached up to $15-30 \%$ during 1-3 weeks of storage. Above results were in line with the outcomes of current study that FR\% in Kinnow mandarin was mainly caused due to infestation of certain fungi. Poor anti-fungal 
treatment and inappropriate long storage may have caused the FR in Kinnow mandarin.

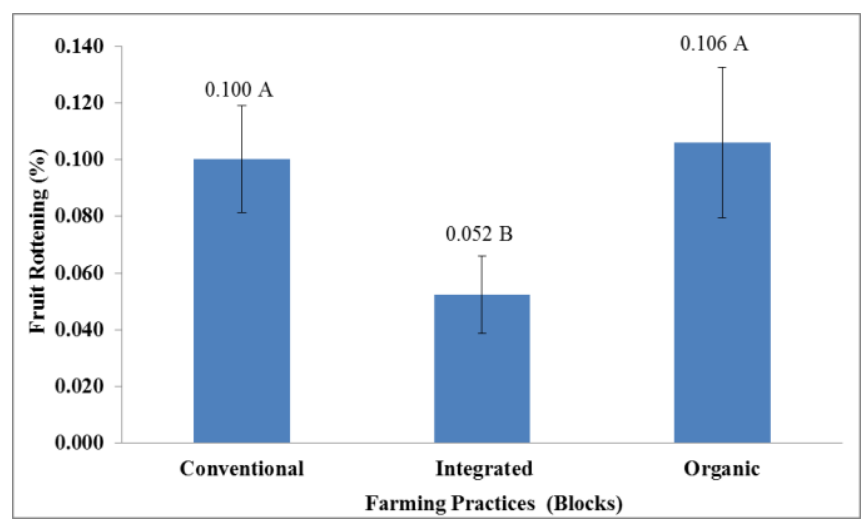

Figure 3. Effect of farming practices (blocks) on fruit rottening (\%) of Kinnow mandarin

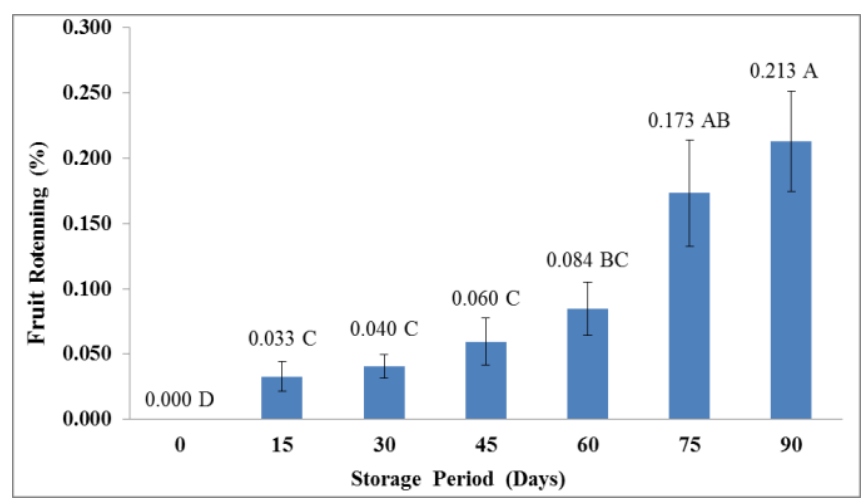

Figure 4. Effect of storage period (days) on fruit rottening $(\%)$ of Kinnow mandarin

Storage characteristics were the prime limiting factors for shelf life performance of different fruits. Fruit rottening can be affected greatly due lowering of the antioxidant activities especially during refrigerated storage (Agostini et al., 2006). It was also expressed that processing or wax coating in citrus fruit had become very necessary to control fruit spoilage and rottening. For remote shipments fruit storage at $4-6^{\circ} \mathrm{C}$ had become mandatory to avoid fruit spoilage. Jan and Rab (2012) concluded that refrigerated storage of citrus fruit might have hold up to 150 days without serious quality deterioration and rottening. Above discussion can be revealed that Kinnow fruit stored under controlled conditions caused to retard fruit spoilage. Treated Kinnow had lower fruit rottening and physiological losses even when subjected to store at maximum time interval of 75-90 days.

Chilling injury percentage (CI \%) of Kinnow mandarin: The results regarding CI revealed that the effect of different farming practices and storage period on $\mathrm{CI} \%$ was found to be highly significant, whereas, the effect of cropping years was found to be non-significant. Moreover, the effect of first order interactions of farming practices, storage period, farming practices and cropping years were also found to be highly significant, however the interactive effect of all farming practices, storage period and cropping years was found to be non-significant.

The effect of farming practices illustrated that significantly the highest CI (\%) was observed in organic farming with mean values of $2.51 \%$ whereas significantly the lowest CI (\%) was noted in integrated farming with mean values of $1.20 \%$ as shown in Table 1.

Gohar et al. (2007) expressed that citrus cultivars were chilling sensitive at low temperature; hence their storage above freezing might have caused certain physiological deteriorations like chilling injury. Amodio et al. (2007) stored kiwifruits for 120 days and noted that conventionally grown fruits had comparatively higher firmness and lower CI like storage disorders than other fruits. These findings were in line with the results of current study that Kinnow grown through conventional and integrated methods might have induced defense system and had comparatively low exposure of $\mathrm{CI}$ and other fruit spoilage. It can also be referred that the effective use of different pesticides and chemical fertilizers during most active and critical stages of Kinnow production might have induced affinity in fruit rind against different biotic and abiotic stresses.

Mathaba et al. (2013) explicated that application of imbalance fertilizers, high $\mathrm{pH}$ and low organic matter in conventionally grown Kinnow might have developed poor fruit rind highly susceptible to rind splitting and CI during storage. Currently in Pakistan the imposition of certain quarantine obligations from different export markets have also popularized the concepts of food safety, MRL (Maximum Residues Limits) and toxicity of pesticides amongst citrus stakeholders. Kinnow growers have become more conscious in selection of pesticides and preferring the integrated management practices which might have compacted the fruits having strong rind and lower CI during cold storage. These observations were in accordance to Thippeswamy (2014) findings that poor peeling of fruits developed due poor fertility of soil was much susceptible to pathogens and CI during long storage.

The combined effect of farming practices and storage period revealed that significantly the highest $\mathrm{CI}$ was observed in organic farming whereas the lowest CI was noted during early storage 15-45 days in all farming products. In current experiment CI (\%) was ranged $0-4.33 \%$ as shown in Table 1. In citrus fruits $\mathrm{CI}$ is the most damaging post-harvest storage physiological disorder which frequently occurs due to freezing and storage at low temperature for long time interval (Henriod et al., 2005). Chan and Tian (2006) briefed that good management and application of balanced inputs during pre-harvest had improved storage performance and lowered down the chilling risks in most of fruits. It was further suggested that CI was mostly caused in fruits having 
poor rind and subjected to long storage at low temperature. These findings were in accord with the observations of current study that fruit grown through integrated farming system on well fertilized soils might have developed the peeling more strong and resistant against rind splitting and chilling effect.

The results also revealed that CI (\%) in Kinnow mandarin was significantly increased with prolonging of storage period (45-90 days) whereas; significantly the lowest CI (\%) was observed during short storage (0-15 days). Chilling injury in current experiment was increased linearly from 1545 storage days later on the chilling intensity was reduced as shown in Table 1.

Henriod et al. (2005) concluded that citrus mandarin was much susceptible to CI which was increased with increasing of storage time. Fonseca and Cinco (2006) expressed that CI in fruit and vegetables increased as storage period was lengthened. These observations were in accordance to the findings of current study. It may also be explained that due to improper storage conditions and genetic vulnerability, rind splitting in Kinnow was induced and its intensity was increased with increasing of storage time.

Mathaba et al. (2013) briefed that citrus farming practices and environmental attributes were major factors determining the chilling receptiveness of lemon fruit. Nukuntoernprakit et al. (2015) explained that CI was changed in pineapple on changing the environmental and storage conditions. Prolonged low temperature might have affected the peeling or rind conditions of fruit. These studies were also agreed with current observations that periodical climatic changes and incidence of unexpected prolonged low temperature observed in Pakistan during last few years may have loosened the rind membrane of Kinnow mandarin and have weakened its stiffness to experience the high CI.

The combined effect of farming practices and cropping years showed that significantly the highest CI (\%) was noted in organic Kinnow during third and first production years, in conventional fruit during second cropping year. In integrated fruit the lowest CI (\%) was observed during third cropping year. In current experiment it was ranged from 0.72 to $2.74 \%$ due to combine effect of farming practices and cropping years as shown in Table 2 .

The combined effect of storage period and cropping years revealed that significantly the highest CI (\%) was noted at storage of 75 days during second cropping year and on storage of 60 days during first cropping year. Similarly, significantly the lowest CI (\%) was observed during early storage of 15-30 days during all three cropping years as shown in Table 2. These results again confirmed that CI (\%) in Kinnow was significantly changed when fruit was subjected for long storage period like more than 45 days as was concluded by Ozdemir et al. (2008). Candir et al. (2013) also expressed that the intensity of CI (\%) was varied when orange was subjected to store on low temperature.
Table 1. Combine effect of farming practices (blocks) and storage period (days) on chilling injury $(\%)$ of Kinnow mandarin

\begin{tabular}{lcccc}
\hline $\begin{array}{l}\text { Storage } \\
\text { Period }\end{array}$ & \multicolumn{2}{c}{ Farming Practices (Blocks) } & \multirow{2}{*}{ Mean } \\
\cline { 2 - 4 } & Conventional & Integrated & Organic & \\
\hline 0 & $0.00 \mathrm{~g}$ & $0.00 \mathrm{~g}$ & $0.00 \mathrm{~g}$ & $0.00 \mathrm{C}$ \\
15 & $0.00 \mathrm{~g}$ & $0.00 \mathrm{~g}$ & $0.00 \mathrm{~g}$ & $0.00 \mathrm{C}$ \\
30 & $2.20 \mathrm{c}-\mathrm{f}$ & $0.13 \mathrm{~g}$ & $1.40 \mathrm{fg}$ & $1.24 \mathrm{~B}$ \\
45 & $3.07 \mathrm{a}-\mathrm{e}$ & $1.80 \mathrm{ef}$ & $3.53 \mathrm{a}-\mathrm{d}$ & $2.80 \mathrm{~A}$ \\
60 & $3.73 \mathrm{a}-\mathrm{c}$ & $2.00 \mathrm{~d}-\mathrm{f}$ & $4.33 \mathrm{a}$ & $3.36 \mathrm{~A}$ \\
75 & $3.53 \mathrm{a}-\mathrm{d}$ & $2.60 \mathrm{~b}-\mathrm{f}$ & $4.13 \mathrm{ab}$ & $3.42 \mathrm{~A}$ \\
90 & $3.73 \mathrm{a}-\mathrm{c}$ & $1.87 \mathrm{ef}$ & $4.20 \mathrm{a}$ & $3.27 \mathrm{~A}$ \\
Mean & $2.32 \mathrm{~A}$ & $1.20 \mathrm{~B}$ & $2.51 \mathrm{~A}$ & \\
\hline
\end{tabular}

Table 2. Combine effect of farming practices (blocks) and crop years on chilling injury $(\%)$ of Kinnow mandarin.

\begin{tabular}{lcccc}
\hline Crop & \multicolumn{2}{c}{ Farming Practices (Blocks) } & \multirow{2}{*}{ Mean } \\
\cline { 2 - 4 } Years & Conventional & Integrated & Organic & \\
\hline Year 1 & $2.23 \mathrm{ab}$ & $1.43 \mathrm{bc}$ & $2.60 \mathrm{a}$ & $2.09 \mathrm{~A}$ \\
Year 2 & $2.46 \mathrm{a}$ & $1.46 \mathrm{bc}$ & $2.20 \mathrm{ab}$ & $2.04 \mathrm{~A}$ \\
Year 3 & $2.29 \mathrm{ab}$ & $0.72 \mathrm{c}$ & $2.74 \mathrm{a}$ & $1.92 \mathrm{~A}$ \\
Mean & $2.32 \mathrm{~A}$ & $1.20 \mathrm{~B}$ & $2.51 \mathrm{~A}$ & \\
\hline
\end{tabular}

Peel pitting percentage (PP\%) of Kinnow mandarin: Peel pitting or cold pitting in citrus fruit is referred as physiological disorder that usually appears as small dark circles on the fruit skin. After 24 hours of invasion these circles turn into brown spots which later on develop into small depressions or pits. These darken spots reduce the external presentation of fruit. In fruits, peel pitting is also correlated with its membrane deterioration (Bajwa and Anjum, 2007).

In current study, results demonstrated that the effect of farming practices and storage period on PP (\%) was found to be highly significant whereas the effect of cropping years on it was found to be non-significant. Furthermore, the first order interaction of farming practices, storage period and cropping years and their interactive effects were also found to be non-significant.

Figure 5 expressed that significantly the highest PP (\%) was noted in organically grown Kinnow and the lowest rind pitting was observed in integrated farming fruit with calculated values of 9.64 and $9.41 \%$ respectively. Conventionally grown Kinnow exhibited $9.61 \%$ of rind pitting and was ranked on second after organic farming.

Candir et al. (2013) conducted same study on oranges and concluded that organically grown fruits showed higher PP (\%) as compared to the conventionally grown oranges. Similarly; many other physicochemical characteristics were also same as were observed in current studies. However, in current study the best performance was noted in integrated fruit which might be because of application of best combination of both farming (organic and conventional) 
practices. Plants grown on enriched and fertile soil might have grown fruit having compacted fruit with strong cell membrane and resistant to most of environmental stresses. Amodio et al. (2007) evaluated the impact of different farming practices on storage performance of fruit. The results revealed that PP like fruit rottening in grapefruits and kiwifruits were almost similar as were illustrated in current studies. Rahemi and Mirdehgan (2004) studied the exposure of temperature conditioning on reducing $\mathrm{PP}$ and other physiological disorders and reported that most of fruit deterioration was decreased when fruit was subjected on controlled conditions. However, it was increased with the increasing of storage time.

Golias and Kanova (2008) reported that storage problems were significantly changed in fruits cultivated in different production systems. Peel pitting in citrus oranges was enhanced on increasing of storage time. The change in storage time had significant impact on PP (\%) in oranges and grapefruit cultivars. Some other researchers also briefed that fruit pitting was caused due to long and poorly managed storage conditions (Alferez et al., 2005). In the light of above discussion and current results it can be concluded that inappropriate storage conditions and time might have lead toward peel pitting like fruit deterioration in Kinnow mandarin.

Figure 6 described that the PP\% in Kinnow mandarin was increased with increasing of storage period. Significantly the highest fruit pitting (15.5\%) was observed when Kinnow was stored at 90 days and the lowest pitting was recorded during early storage interval (0-15 days). Arpaia and Kader (2000) described similar results that the severity of peel pitting in citrus fruit was increased increasing of storage interval.

Peel pitting or cold pitting in citrus is mostly observed during 2-4 days of cold storage. It increases most rapidly during long storage especially during first two weeks (10-15 days). Peel pitting like physiological deterioration is very much associated with high temperature in cold store (Dou and Ismael, 2000). Alferez et al. (2005) described that citrus tangerine stored for long time interval had induced peel pitting as compared to short interval storage. Plaza et al. (2004) also briefed that fruit pitting in mandarin was mainly caused during long post-harvest storage. Fruit rottening was further induced in adequate storage conditions.

In the light of above discussion and the results of current study it can be concluded that PP in fresh Kinnow mandarin can be lowered down through reducing the storage interval and expediting the processing and packaging soon after harvesting. Adequate storage of waxed treated Kinnow at 4$10^{\circ} \mathrm{C}$ can maintain its quality for long time without deteriorating its physical appearance. It can also be concluded that fruit pitting in Kinnow mandarin was increased with increasing the storage time.

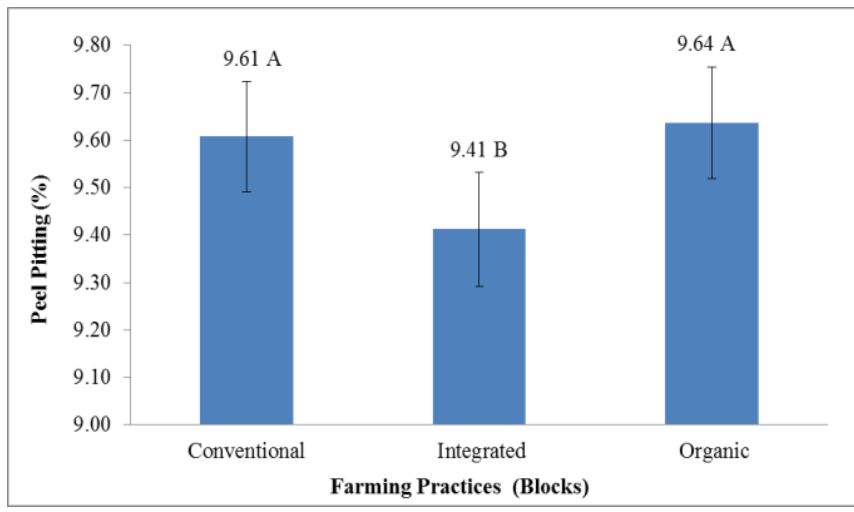

Figure 5. Effect of farming practices (blocks) on peel pitting (\%) of Kinnow mandarin

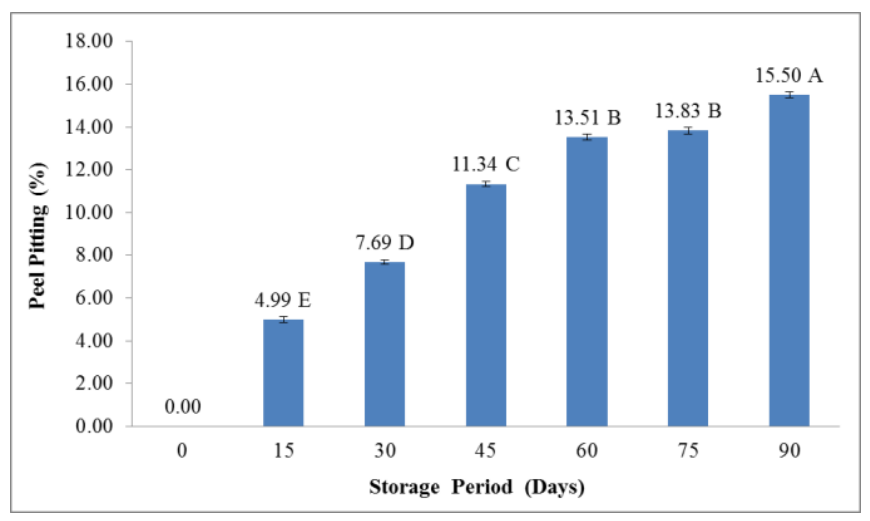

Figure 6. Effect of storage period (days) on peel pitting (\%) of Kinnow mandarin

Conclusions: Kinnow mandarin grown through nonconventional farming systems (organic and integrated) had competitive storage performance to conventionally grown fruit. Fruits grown through organic and integrated systems performed superiorly in most of the physiological disorders including physiological loss in weight, chilling injury, fruit rottening and peel pitting observed during cold storage. All of the physiological characteristics of Kinnow mandarin grown through any of the farming systems were deteriorated with increasing of storage interval. Comparative storage performance of organic and integrated fruit depicted the successful conversion potential of farming system and its adoptability in Kinnow mandarin in Pakistan. It is suggested to carry out some more studies to evaluate the physiochemical and nutritional characteristics of Kinnow mandarin grown through both conventional and nonconventional farming systems.

Acknowledgement: This research was supported by Roshan Enterprisers and Wahdat Citrus Farms. 


\section{REFERENCES}

Agostini, J.P., N.A. Peres, S.J. Mackenzie, J.E. Adaskaveg and L.W. Timmer. 2006. Effect of fungicides and storage conditions on postharvest development of citrus black spot and survival of Guignardia citricarpa in fruit tissues. Plant Dis. 90:1419-1424.

Alferez, F., L. Zachariah and J. Burns. 2005. Low relative humidity at harvest and before storage at high humidity influence the severity of postharvest peel pitting in citrus fruit. J. Am. Soc. Hort. Sci. 130:225-231.

Ali, A., M. Abrar, M.T. Sultan, A. Din and B. Niaz. 2011. Post-harvest physicochemical changes in full ripe strawberries during cold storage. J. Anim. Plant Sci. 21:38-41.

Amodio, M.L., G. Colelli, J.K. Hasey and A.A. Kader. 2007. A comparative study of composition and postharvest performance of organically and conventionally grown kiwifruits. J. Sci. Food Agric. 87:1228-1236.

Arpaia, M.L. and A.A. Kader. 2000. Mandarin/Tangerine. Recommendations for maintaining postharvest quality. Available online

at: http://postharvest.ucdavis.edu/produce/producefacts/frui $\mathrm{t} / \mathrm{mandarin} \cdot \mathrm{html}$.

Bajwa, B.E. and F.M. Anjum. 2007. Improving storage performance of Citrus reticulata Blanco mandarins by controlling some physiological disorders. Int. J. Food Sci. Tech. 42:459-501.

Biruk, M. Z., R. Nigussie-Dechassa, A. Bekele, A. Yibekal and T. Tamado. 2014. Influence of combined application of inorganic $\mathrm{N}$ and $\mathrm{P}$ fertilizers and cattle manure on quality and shelf-life of potato (Solanum tuberosum L.) tubers. J. Posthar. Technol. 2:152-168.

Camin, F., M. Perini, L. Bontempo, S. Fabroni, W. Faedi, S. Magnani, G. Baruzzi, M. Bonoli, M.R. Tabilio, S. Musmeci, A. Rossmann, S.D. Kelly and P. Rapisarda. 2011. Potential isotopic and chemical markers for characterizing organic fruits. Food Chem. 125:10721082.

Candir, E., M. Kamiloglu, D. Ustun and G.T. Kendir. 2013. Comparison postharvest quality of conventionally and organically grown 'Washington Navel' oranges. J. App. Bot. Food Quali. 86:59-65.

Chan, Z. and S. Tian. 2006. Induction of $\mathrm{H}_{2} \mathrm{O}_{2}$-metabolizing enzymes and total protein synthesis by antagonist and salicylic acid in harvested sweet cherry fruit. Posthar. Biol. Technol. 39:314-320.

Chopra, S., S.K. Aleksha, H.S. Oberoi, A.K.U. Mahmood and J. Kaur. 2004. Performance evaluation of evaporative cooled room for storage of Kinnow mandarin. J. Food Sci. Technol. 14:573-577.

D’Aquino, S., M. Schirra, A. Palma, M.C. Strano and G. Lanza. 2007. Postharvest decay control of citrus fruit following treatments with GRAS compounds or with novel fungicides at 20 or $50^{\circ} \mathrm{C}$. Italus Hortus 14:52-55.

Dou, H. and M.A Ismael. 2000. Effect of pre-cooling and storage temperature on post- harvest pitting incidence of citrus; p.131-142. In: W.J. Florkowska, S.E Prussia and R.L Shewfelt (eds.), Integrated view of fruit and vegetable quality. Technomic Pub. Co. Inc. Lancaster, Basel.

FAO. 2012. Searchable online statistical database from FAO (Food and Agriculture Organization), Division of the United Nations. Rome, Italy. Available online on http://faostat.fao.org/site//567/Desktopdefault.aspx?Pag elI $=567$ \#ancor

Fonseca, J.M. and R.A. Cinco. 2006. Evaluation of commercial alternatives to reduce postharvest pitting of organically grown zucchini and cucumber. Acta Hort. 712:291-298.

Gichuhi, P.N., A.K. Kpomblekou and A.C. BovellBengamin. 2014. Nutritional and physical properties of organic Beauregard sweet potato [(Ipomoea batatas (L.)] as influenced by broiler litter application rate. Food Sci. Nutr. 2:332-340.

Gohar, A.K., A. Rab, M. Sajid and S. Ullah. 2007. Effect of heat and cold treatments on post-harvest quality of sweet orange cv. Bloodred. Sarhad J. Agric. 23:67-72.

Golias, J.P. and J. Kanova. 2008. Effect of low oxygen storage conditions on volatile emission and anaerobic metabolite concentrations in tow plum fruit cultivars. HortScience 37:145-154.

Grosser, J.W., P. Ollitrault and O. Olivares-Fuster. 2000. Somatic hybridization in citrus: an effective tool to facilitate variety improvement. In Vitro Cellular Develop. Biol. 36:434-449.

Hajslova, J., V. Schulzova, P. Slanina, K. Janne, K.E. Hellenas and C.H. Andersson. 2005. Quality of organically and conventionally grown potatoes: Fouryear study of micronutrients, metals, secondary metabolites, enzymic browning and organoleptic properties. J. Food Add. Contami. 22:514-534.

Henriod, R.D, M.R. Gibberd and M.T. Treeby. 2005. Storage temperature effects on moisture loss and the development of chilling injury in lanes late navel orange. Aust. J. Exp. Agric. 45:453-458.

Iglesias, D.J., M. Cercos, J.M. Colmenero-Flores, M.A. Naranjo, G. Rios, E. Carrera, O. Ruiz-Rivero, I. Lliso, R. Morillon, F.R. Tadeo and M. Talon. 2007. Physiology of citrus fruiting. Brazil J. Plant Physiol. 19:333-362.

Ioannis, E.P., E. Protopapadakis, K.N. Dimassi and I.N. Therios. 2004. Nutritional status, yield and fruit quality of "Encore" mandarin trees grown in two sites of an orchard with different soil properties. J. Plant Nutr. 27:1505-1515. 
Jan, I. and A. Rab. 2012. Influence of storage duration on physico-chemical changes in fruit apple cultivars. J. Anim. Plant Sci. 22:708-714.

Lafuente, M.T., M. Tellez and M.A. Zacarias. 1997. Abscisic acid in the response of 'Fortune' mandarin to chilling. Effect of maturity and high temperature conditioning. J. Sci. Food Agric. 73:494-502.

Malik, M.N. 1994. Horticulture, $1^{\text {st }}$ Ed. National Book Foundation, Islamabad, Pakistan.

Marcilla, A., M. Zarzo and M.A. Rio. 2006. Effect of storage temperature on the flavour of citrus fruit. Span. J. Agric. Res. 4:336-344.

Mathaba, N., I. Bertling and J.P. Bower. 2013. Chilling injury in citrus fruit: A holistic view. Acta Hort. 1007:103-110.

Nukuntoernprakit, O., K. Chanjirakul, W.G. van Doorn and J. Siriphanich. 2015. Chilling injury in pineapple fruit: Fatty acid composition and antioxidant metabolism. Posthar. Biol. Technol. 99:20-26.

Ozdemir, M., B. Ozen, L. Dock and J. Floros. 2008. Optimization of osmotic dehydration of diced green peppers by response surface methodology. LTW- Food Sci. Technol. 41:2044-2050.

Peter, G., F. Graham and E.O. John. 2002. Some important postharvest pathogens. Posthar. Biol. Technol. 1:539544.

PHDEB. 2013. Citrus Marketing Strategy. Pakistan Horticulture Development \& Export Company. Available online http://www.phdeb.org.pk/MktStrategies/Citrus.pdf

Plaza, P., A. Sanbruno, J. Usall, N. Lamarca, R. Torres, J. Pons and I. Vinas. 2004. Integration of curing treatments with degreening to control the main postharvest diseases of Clementine mandarins. Posthar. Biol. Technol. 34:29-37.

Rab, A., S. Haq, S.A. Khalil and S.G. Ali. 2010. Fruit quality and senescence related changes in sweet orange cultivar Blood red uni-packed in different packing materials. Sarhad J. Agric. 26:221-227.

Rahemi, M. and S.H. Mirdehgan. 2004. Effect of temperature conditioning on reducing chilling injury of pomegranate fruits during storage. Acta Hort. 662: 8791.

Rajendra, B.N., A.R. Kurubar, G.H. Anasubai and K.M. Swamy. 2013. Influence of organic manures and inorganic fertilizers on vegetative development, yield, shelf-life traits and sensory evaluation score of acid lime (Citrus aurantifolia Christm.) cv. Kagzi. Asian J. Hort. 8:183-187.

Ranjit, C. and P.K. Paul. 2013. Impact of organic amendments and inorganic fertilizers on post-harvest storage life and organoleptic quality of tomato under eastern Himalayan region. Disco. Agri. 1:39-42.

Roth, E., A. Berna, K. Beullens, S. Yarramraju, J. Lammertyn, A. Schenk and B. Nicolai. 2007. Postharvest quality of integrated and organically produced apple fruit. Posthar. Biol. Technol. 45:11-19.

Roussos, P.A. 2011. Phytochemicals and antioxidant capacity of orange (Citrus sinensis (L.) Osbeck cv. Salustiana) juice produced under organic and integrated farming system in Greece. Sci. Hortic. 129:253-259.

Saeed, A., S. Zora, S.K. Ahmad and Z. Iqbal. 2013. Preharvest application of salicylic acid maintains the rind textural properties and reduce fruit rot and chilling injury of sweet orange during cold storage. Pak. J. Agri. Sci. 50:559-569.

Sala, J.M., M.T. Sanchez-Ballesta, F. Alferez, M. Mulas, L. Zacarias and M.T. Lafuente. 2005. A comparative study of the postharvest performance of an ABA-deficient mutant of oranges: II. Antioxidant enzymatic system and phenylalanine ammonia-lyase in non-chilling and chilling peel disorders of citrus fruit. Posthar. Biol. Technol. 37:232-240.

Smilanick, J.L, G.E. Brown and J.W. Eckert. 2006. Postharvest citrus diseases and their control. In: W.F. Wardowski, W.M. Miller, D.J. Hall and W. Grierson (eds.), Fresh Citrus Fruits ( $2^{\text {nd }}$ Ed.). Longboat Key, FL, USA: Florida Science Source Inc. pp. 339-396.

Thakur, K.S., B.B.L. Kaushal and R.M. Sharma. 2002. Effects of different post-harvest treatments and storage conditions on the fruit quality of Kinnow. J. Food Sci. Tech. 39:609-618.

Thippeswamy, E. 2014. Inclusive growth and organic farming in Shimoga, district of Karnataka. Int. J. Sci. Res. 4: 9-16.

Willer, H. and L. Kilcher. 2011. The World of organic agriculture- Statistics and emerging trends 2011. IFOAM and FiBL, Bonn, Germany and Frick, Switzerland. 